\title{
Structure of the TAPBPR-MHC I complex defines the mechanism of peptide loading and editing
}

\author{
Christoph Thomas ${ }^{1 *}$ and Robert Tampé ${ }^{1,2 *}$ \\ ${ }^{1}$ Institute of Biochemistry, Biocenter, Goethe University Frankfurt, Max-von-Laue Strasse 9, 60438 Frankfurt/Main, Germany. ${ }^{2}$ Cluster of Excellence-Macromolecular \\ Complexes, Goethe University Frankfurt, Max-von-Laue Strasse 9, 60438 Frankfurt/Main, Germany. \\ ${ }^{*}$ Corresponding author. E-mail: c.thomas@em.uni-frankfurt.de (C.T.); tampe@em.uni-frankfurt.de (R.T.)
}

Adaptive immunity is shaped by a selection of peptides presented on major histocompatibility complex class I (MHC I) molecules. The chaperones Tapasin (Tsn) and TAP-binding protein-related (TAPBPR) facilitate MHC I peptide loading and high-affinity epitope selection. Despite the pivotal role of Tsn and TAPBPR in controlling the hierarchical immune response, their catalytic mechanism remains unknown. Here, we present the X-ray structure of the TAPBPR-MHC I complex, which delineates the central step of catalysis. TAPBPR functions as peptide selector by remodeling the MHC I $\alpha 2-1$-helix region, stabilizing the empty binding groove, and inserting a loop into the groove that interferes with peptide binding. The complex explains how mutations in MHC I-specific chaperones cause defects in antigen processing and suggests a unifying mechanism of peptide proofreading.

The adaptive immune system is able to detect and eliminate cells that are malignantly transformed or infected by intracellular pathogens. Specific immune reactions against these cells are triggered at the cell surface by selected peptide epitopes presented on MHC I molecules that are scanned by cytotoxic T lymphocytes (1-6). Despite its significance for eliciting specific immune responses, the molecular mechanisms underlying antigenic peptide selection in processes such as tumor surveillance, infectious disease defense, and autoimmunity, remain elusive. The loading of antigenic peptides onto MHC I is known to be coordinated by the peptide-loading complex (PLC) in the endoplasmic reticulum (ER) $(3,7)$. In particular, the MHC Ispecific chaperone Tsn, an integral component of the PLC, accelerates peptide loading and selects peptides for their ability to form stable complexes with MHC I, a process called peptide proofreading or editing (8-13). The selection of high-affinity peptide epitopes on MHC I molecules is essential for T-cell differentiation in the thymus, naïve $\mathrm{T}$ lymphocyte priming in the lymph node, and final long-term scanning of target cells by effector T cells. Recently, a PLCindependent Tsn homolog called TAPBPR has been shown to act as a second MHC I-specific peptide proofreader (1417). Site-directed mutagenesis experiments indicate that Tsn and TAPBPR share similar binding interfaces on MHC I (17, 18), suggesting a common catalytic mechanism. Despite the central role of Tsn and TAPBPR in the antigen presentation pathway and in shaping the hierarchical immune response (19-21), the molecular events taking place during catalyzed peptide loading and proofreading on MHC I are unknown, largely due to the lack of structural information on MHC I in complex with these chaperones.

To gain insights into the molecular basis of peptide proofreading catalysis, we determined the X-ray structure of TAPBPR in complex with MHC I heavy chain (hc) and $\beta 2-$ microglobulin ( $\beta 2 \mathrm{~m})$ (Fig. 1A). Since TAPBPR and Tsn interact with peptide-MHC I transiently, forming stable complexes only with peptide-free MHC I, and since empty MHC I molecules are intrinsically unstable (22), we deployed the following strategy for complex formation: the MHC I hc was refolded in the presence of purified $\beta 2 \mathrm{~m}$ and a photocleavable high-affinity peptide. Peptide cleavage by UV irradiation was subsequently carried out in the presence of purified TAPBPR (Fig. 1B) (23). This photo-triggered approach enabled us to isolate and crystallize a heterotrimeric TAPBPR-MHC I editing complex, consisting of human TAPBPR, mouse $H 2-\mathrm{D}^{\mathrm{b}}$, and human $\beta 2 \mathrm{~m}$. X-ray data were collected to a resolution of $3.3 \AA$ (table S1).

The overall architecture of TAPBPR consists of an Nterminal composite domain with coalesced seven-stranded $\beta$ barrel and immunoglobulin (Ig)-like (V type) folds, and a Cterminal $\mathrm{IgC} 1$ domain. With its large concave surface, the $\mathrm{N}$ terminal domain of TAPBPR encompasses the $\alpha 2-1$ helix region of the MHC I heavy chain (Fig. 1A and fig. S1). At one end of this $\mathrm{N}$-terminal interface, a $\beta$-hairpin of TAPBPR reaches under the floor of the peptide-binding groove establishing ionic and polar interactions with residues of strands $\beta 6, \beta 7$, and $\beta 8$. Notably, the tip of the $\beta$-hairpin contacts $\beta 2 \mathrm{~m}$ at the loop between $\beta 4$ and $\beta 5$ (Fig. 1C). Because of its resemblance to a jack acting on the underside of a car, we named this $\beta$-hairpin the "jack hairpin". The $\alpha 2-1$ helix contacts with TAPBPR are dominated by van der Waals interac- 
tions and characterized by a relatively small number of hydrogen bonds. One strong hydrogen bond, as judged from its geometry and the distance between H-bond donor and acceptor, is formed between the side chain of Q275 ${ }^{\mathrm{TAPBPR}}$ and the main-chain carbonyl oxygen of $\mathrm{A} 135^{\mathrm{MHC}}$, which is located at the end of the $\beta 8$ strand just before the $\alpha 2-1$ helix (Fig. 1D and fig. S2). One feature of the N-terminal interface is an extended loop in TAPBPR containing a short $\alpha$ helix that dives into the MHC peptide-binding groove (Fig. 1, A and D). Because of its functional role in the catalytic mechanism of TAPBPR, we termed this loop the "scoop loop". The interface formed between the N-terminal domain of TAPBPR and the MHC I buries a total surface area of $2,842 \AA^{2}$ (hc: $90 \%$, $\beta 2 \mathrm{~m}: 10 \%)$. Contrary to what molecular dynamics simulations predicted (24), the C-terminal domain of TAPBPR interacts with both the $\alpha 3$ domain of the heavy chain and $\beta 2 \mathrm{~m}$, covering up a total surface area of $1,498 \AA^{2}$ (hc: $41 \%$, $\beta 2 \mathrm{~m}: 59 \%)$. The interface with the $\alpha 3$ domain is characterized by a short stretch of antiparallel $\beta$-sheet-like contacts between the protein backbones around $\mathrm{Q} 339^{\mathrm{TAPBPR}}$ and $\mathrm{L} 230^{\mathrm{MHC}}$. Ionic and polar side-chain interactions are formed between R338 ${ }^{\mathrm{TAPBPR}}$, S346 ${ }^{\mathrm{TAPBPR}}$, and E229 ${ }^{\mathrm{MHC}}$ (fig. S3). The interface with $\beta 2 \mathrm{~m}$ involves backbone interactions between F334 ${ }^{\text {TAPBPR }}$ and $192^{\beta 2 m} / \mathrm{K} 94^{{ }^{22 m}}$ and between L337 ${ }^{\mathrm{TAPBPR}}$ and $\mathrm{I} 7^{\beta 2 \mathrm{~m}}$, and the side chain of S336 $6^{\mathrm{TAPBPR}}$ forms hydrogen bonds to the main chain of $\mathrm{V}^{\beta 2 \mathrm{~m}}$ (fig. S4). The interface is further stabilized by a hydrogen bond between $\mathrm{D} 312^{\mathrm{TAPBPR}}$ and $\mathrm{T} 4^{\beta^{2 m}}$. A comparison of the TAPBPR-MHC I structure with available structures of classical and non-classical MHC I molecules in complex with different interaction partners shows that the binding mode of TAPBPR is unique (fig. S5). Remarkably, the total surface area buried in the TAPBPRMHC I complex is significantly larger than in all other known MHC I complexes.

The TAPBPR-MHC I structure allows us to readily explain the physiological impact of mutations originally described for Tsn (18) and later confirmed for TAPBPR (16): the TN6 mutant, in which the invariant residues E208, R210, Q212, and Q275 (fig. S6) were altered to Lys (E208K), Glu (R210E), and Ser (Q212S and Q275S), abrogates binding and peptide loading onto MHC I. Our structure shows that R210 and Q212 are part of the jack hairpin and form multiple interactions with MHC I heavy chain residues (Fig. 1C). A charge reversal and a change to Ser, respectively, as in the TN6 mutant, are expected to destroy these interactions and possibly result in electrostatic repulsion. Q275 is engaged in the strong hydrogen bond of the $\alpha 2-1$ interface (Fig. 1D); a serine at position 275 is unable to maintain this interaction. Similar to the TN6 mutant, changing R338 (TC2 mutant) or Q339 and S340 (TC3 mutant) to Asp completely abolished MHC I binding (17). These mutations are anticipated to cause electrostatic repulsion with E229 and to destroy the main-chain interactions with $\mathrm{L} 230^{\mathrm{MHC}}$ in the $\alpha 3$ interface (fig. S3).

The MHC I-binding groove in the TAPBPR complex is devoid of peptide. The structure thus shows for the first time a conformation of a classical MHC I molecule in its peptide-free state. A superposition of the peptide-bound H2$\mathrm{D}^{\mathrm{b}}$ (PDB ID: 2F74) (25) with the TAPBPR-H2- $\mathrm{D}^{\mathrm{b}}$ complex reveals that the peptide-binding groove is significantly widened (Fig. 2A). The opening is due to an outward and downward movement of the $\alpha 2$ helices (displacement of Q149 $\mathrm{C} \alpha$ : $6.3 \AA$ ), which is accompanied by a partial downward shift of the $\beta$ strands forming the floor of the peptidebinding groove (Fig. 2B). The interaction with TAPBPR also leads to a repositioning of $\beta 2 \mathrm{~m}$ (Fig. $2 \mathrm{C}$ ), which, in turn, breaks up old and establishes new interactions with the heavy chain. Lost interactions comprise the salt bridge

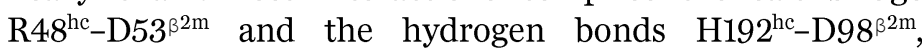
$\mathrm{R} 202^{\mathrm{hc}}-\mathrm{D} 98^{\mathrm{\beta} 2 \mathrm{~m}, \mathrm{mc}}$, and $\mathrm{G} 120^{\mathrm{hc}, \mathrm{mc}}-\mathrm{R} 3^{{ }^{32 \mathrm{~m}}}$ (mc: main chain). Newly formed interactions include the hydrogen bonds $\mathrm{Y} 27^{\mathrm{hc}}-\mathrm{F} 56^{\beta^{2 \mathrm{~m}, \mathrm{mc}}}, \mathrm{Y}_{11} 3^{\mathrm{hc}}-\mathrm{K} 58^{\beta^{2 \mathrm{~m}}}$, and $\mathrm{P} 235^{\mathrm{hc}, \mathrm{mc}}-\mathrm{N} 24^{\beta^{2 \mathrm{~m}}}$.

The widened conformation of the peptide-binding groove is stabilized by contacts of the $\alpha 2-1$ helix region with the concave surface of the TAPBPR N-terminal domain and by the scoop loop; the latter wedges into the peptide-binding groove and occupies a position that collides with bound peptide and highly conserved MHC I residues coordinating the $\mathrm{C}$ terminus of the peptide near the $\mathrm{F}$ pocket, including Y84, T143, K146, and W147 (Fig. 2, A and D, and fig. S1C and fig. S7). In the peptide-free TAPBPR complex, T143 and K146 in the shifted $\alpha 2-1$ helix are hydrogen bonded with mainchain atoms of the scoop loop. The side chain of Y84 is forced by the scoop loop to swing out of the binding groove. The new side-chain conformation of Y84 is stabilized by a hydrogen bond to E105 of TAPBPR. Interestingly, this glutamate is conserved in Tsn (E72) (fig. S6), and when substituted for lysine, it interferes with MHC I binding and reduces the catalytic activity of Tsn (18). In this context, it is important to note that the interactions of MHC I residues with the $\mathrm{N}$ and $\mathrm{C}$ termini of the peptide make the largest contribution to the peptide-binding affinity (26). In particular, the $\mathrm{F}$ pocket region governs the conformational and thermodynamic properties of the binding groove, and the binding of the peptide $\mathrm{C}$ terminus is critically important in establishing the peptide-bound state of MHC I molecules (27). Our structural observations are supported by kinetic analyses, which pointed to a widening of the binding groove during catalyzed peptide selection (12). Apart from the contacts with key peptide-coordinating MHC I residues, the scoop loop of TAPBPR is also connected to the $\alpha 1$ helix of the MHC I via a carbonyl-mediated hydrogen bond to a tryptophan residue (W73). As this tryptophan is not conserved among different MHC I molecules (fig. S7), it may 
contribute to the allomorph-specific binding and catalysis of TAPBPR.

TAPBPR and Tsn are most likely to share the same binding mode on MHC I hc and $\beta 2 \mathrm{~m}$ (fig. S1B) $(17,18)$. A superposition of Tsn from the Tsn-ERp57 structure (18) onto the MHC I-bound TAPBPR uncovers that conformational changes upon binding are not restricted to MHC I, but also take place in the peptide editors. The most significant changes are observed in the position of the C-terminal domain and in the jack hairpin (Fig. 3A), which is the most highly conserved structural element within the editors (fig. S6). Notably, the jack hairpin in Tsn clashes with residues in the floor of the peptide-binding groove; it therefore has to rearrange in order to establish the N-terminal interface of Tsn with MHC I (Fig. 3B). As far as the C-terminal domain is concerned, an extensive rigid-body movement relative to the N-terminal domain of Tsn is necessary in order to form the observed contacts with both the $\alpha 3$ domain and $\beta 2 \mathrm{~m}$ (Fig. 3C). The multiple conformational changes in the MHC I and the peptide editors upon complex formation highlight the importance of protein plasticity in the catalysis of peptide exchange (28) and may explain why attempts to correctly predict the Tsn-MHC I complex in silico have been unsuccessful so far. Based on our X-ray structure, the complex between Tsn-ERp57 and MHC I can be modeled, in which ERp57 is accommodated without any steric clashes (Fig. 3D). The N-terminal interface with MHC I contains a loop segment that is stabilized in Tsn by its association with ERp57 (residues 77-83), but that is disordered in TAPBPR.

The insights gained from the TAPBPR-MHC I complex allow us to propose the following general mechanism of peptide loading and proofreading on MHC I (Fig. 4): the peptide editors sample the quality of MHC I-bound epitopes with respect to their affinity by scanning the $\alpha 2-1$ helix region, a structural element involved in anchoring the $\mathrm{C}$ terminus of the peptide. Upon encountering a sub-optimally loaded MHC I molecule, the editors stabilize a widened conformation of the peptide-binding groove by acting on the $\alpha 2-1$ helix region through the concave surface of their Nterminal domain and the jack hairpin. The scoop loop simultaneously lowers the peptide affinity by displacing and competing for key peptide-coordinating residues (Y84, T143, K146, and W147). These actions induce peptide dissociation and stabilize the resulting high-energy intermediate of the empty MHC I. In the peptide-free state observed in our complex, the scoop loop can be regarded as a surrogate for the $\mathrm{C}$ terminus of the peptide, contributing to the stabilization of the empty peptide-binding groove and the chaperoning effect of TAPBPR/Tsn. Subsequently, only optimal highaffinity epitopes are able to displace the scoop loop and compete with the editor over the $\alpha 2-1$ helix region to restore the tightened conformation of the binding groove, which lowers the affinity of the editor for MHC I and leads to its dissociation. Because of the scoop loop blocking the F pocket, the $\mathrm{N}$-terminal part of the replacement peptide is expected to be involved in the initial steps of the binding event. The result of the editor-catalyzed peptide exchange is an MHC I-bound peptide repertoire enriched with highaffinity epitopes which are able to elicit a hierarchical immune response. In essence, the mechanism of peptide proofreading can be considered a tug-of-war between the peptide and the editor over peptide-coordinating residues of the binding groove and over the $\alpha 2-1$ helix region. In contrast to TAPBPR and Tsn, the MHC II-specific peptide proofreader HLA-DM acts at the opposite end of the binding groove, competing with the N-terminal region of epitope for residues around the P1 pocket of MHC II (29). However, the unifying theme in the activity of MHC I and MHC II exchange catalysts is that both use malleable structural elements flanking the peptide-binding groove to stabilize the empty groove in a state that only high-affinity epitopes are able to overcome.

Despite their common catalytic activity and mechanism, TAPBPR and Tsn exhibit different allomorph specificities $(15,16)$ and are unable to compensate for each other in vivo $(8,11,30)$. We detected structural features in functionally important regions that distinguish Tsn from TAPBPR and may contribute to the differences: one characteristic feature is the aforementioned loop segment in the N-terminal interface that is stabilized in Tsn by the presence of ERp57, but that is disordered in TAPBPR (Fig. 3D), which does not associate with ERp57 (14). Furthermore, since parts of ERp57 around the intermolecular disulfide bond come close to the $\mathrm{C}$ terminus of the $\alpha 2-1$ helix, the direct involvement of ERp57 in MHC I binding and catalysis cannot be excluded. Notably, ERp57 is known to be crucial for the activity of Tsn (13). Moreover, the scoop loop in TAPBPR is significantly longer than in Tsn (fig. S6), suggesting that the peptide selection process carried out by the scoop loop is more stringent in TAPBPR. These differences between TAPBPR and Tsn may have evolved as a result of the distinct cellular environments these proteins are operating in: TAPBPR is not restricted to the ER, but is also found in the Golgi compartment (14) and appears to act as a final gatekeeper in quality control downstream of the Tsn-harboring PLC. These MHC I allomorphs are recognized by TAPBPR as being bound to low-affinity cargo and cannot be loaded with higher-affinity peptide (e.g., due to a shortage of suitable peptides) (15). They are reglucosylated by the TAPBPRassociated glucosyltransferase UGT1 (31) so they are rerouted back to the PLC for a new round of editing. Thus, TAPBPR appears to optimize MHC I peptide ligands not only through its intrinsic peptide proofreading activity, but also by assisting in the UGT1-mediated recycling of peptide- 
deficient MHC I molecules (31). Because the PLC offers more proofreading options, Tsn appears less stringent, indicated by the shorter scoop loop. Further studies will be required to understand the interplay between TAPBPR and Tsn.

The current work uncovers the mechanistic underpinnings of how TAPBPR and Tsn select high-affinity peptide epitopes, which are pivotal in shaping the adaptive immune response with wide-ranging implications for autoimmunity, infection control, transplantation, and cancer immunotherapies. This structure of an MHC I chaperone complex lays the ground for new theoretical and experimental approaches to predict and fine-tune the selection of epitopes and of MHC I molecules based on their intrinsic local and global conformational plasticity.

\section{REFERENCES AND NOTES}

1. O. Rötzschke, K. Falk, K. Deres, H. Schild, M. Norda, J. Metzger, G. Jung, H.-G. Rammensee, Isolation and analysis of naturally processed viral peptides as recognized by cytotoxic $T$ cells. Nature 348, 252-254 (1990). doi:10.1038/348252a0 Medline

2. H. Matsushita, M. D. Vesely, D. C. Koboldt, C. G. Rickert, R. Uppaluri, V. J. Magrini, C. D. Arthur, J. M. White, Y.-S. Chen, L. K. Shea, J. Hundal, M. C. Wendl, R. Demeter, T. Wylie, J. P. Allison, M. J. Smyth, L. J. Old, E. R. Mardis, R. D. Schreiber, Cancer exome analysis reveals a T-cell-dependent mechanism of cancer immunoediting. Nature 482, 400-404 (2012). doi:10.1038/nature10755 Medline

3. J. S. Blum, P. A. Wearsch, P. Cresswell, Pathways of antigen processing. Annu. Rev. Immunol. 31, 443-473 (2013). doi:10.1146/annurev-immunol-032712095910 Medline

4. P. J. Bjorkman, M. A. Saper, B. Samraoui, W. S. Bennett, J. L. Strominger, D. C. Wiley, Structure of the human class I histocompatibility antigen, HLA-A2. Nature 329, 506-512 (1987). doi:10.1038/329506a0 Medline

5. P. J. Bjorkman, M. A. Saper, B. Samraoui, W. S. Bennett, J. L. Strominger, D. C. Wiley, The foreign antigen binding site and $T$ cell recognition regions of class I histocompatibility antigens. Nature 329, 512-518 (1987). doi:10.1038/329512a0 Medline

6. D. R. Madden, The three-dimensional structure of peptide-MHC complexes. Annu. Rev. Immunol. 13, 587-622 (1995). doi:10.1146/annurev.jy.13.040195.003103 Medline

7. S. Hulpke, R. Tampé, The MHC I loading complex: A multitasking machinery in adaptive immunity. Trends Biochem. Sci. 38, 412-420 (2013). doi:10.1016/j.tibs.2013.06.003 Medline

8. A. P. Williams, C. A. Peh, A. W. Purcell, J. McCluskey, T. Elliott, Optimization of the MHC class I peptide cargo is dependent on tapasin. Immunity 16, 509-520 (2002). doi:10.1016/S1074-7613(02)00304-7 Medline

9. M. Howarth, A. Williams, A. B. Tolstrup, T. Elliott, Tapasin enhances MHC class I peptide presentation according to peptide half-life. Proc. Natl. Acad. Sci. U.S.A. 101, 11737-11742 (2004). doi:10.1073/pnas.0306294101 Medline

10. B. Sadasivan, P. J. Lehner, B. Ortmann, T. Spies, P. Cresswell, Roles for calreticulin and a novel glycoprotein, tapasin, in the interaction of MHC class I molecules with TAP. Immunity 5, 103-114 (1996). doi:10.1016/S10747613(00)80487-2 Medline

11. B. Ortmann, J. Copeman, P. J. Lehner, B. Sadasivan, J. A. Herberg, A. G. Grandea, S. R. Riddell, R. Tampé, T. Spies, J. Trowsdale, P. Cresswell, A critical role for tapasin in the assembly and function of multimeric MHC class I-TAP complexes. Science 277, 1306-1309 (1997). doi:10.1126/science.277.5330.1306 Medline

12. M. Chen, M. Bouvier, Analysis of interactions in a tapasin/class I complex provides a mechanism for peptide selection. EMBO J. 26, 1681-1690 (2007). doi:10.1038/sj.emboj.7601624 Medline

13. P. A. Wearsch, P. Cresswell, Selective loading of high-affinity peptides onto major histocompatibility complex class I molecules by the tapasin-ERp57 heterodimer.
Nat. Immunol. 8, 873-881 (2007). doi:10.1038/ni1485 Medline

14. L. H. Boyle, C. Hermann, J. M. Boname, K. M. Porter, P. A. Patel, M. L. Burr, L. M. Duncan, M. E. Harbour, D. A. Rhodes, K. Skjødt, P. J. Lehner, J. Trowsdale, Tapasin-related protein TAPBPR is an additional component of the MHC class I presentation pathway. Proc. Natl. Acad. Sci. U.S.A. 110, 3465-3470 (2013). doi:10.1073/pnas.1222342110 Medline

15. C. Hermann, A. van Hateren, N. Trautwein, A. Neerincx, P. J. Duriez, S. Stevanović, J. Trowsdale, J. E. Deane, T. Elliott, L. H. Boyle, TAPBPR alters MHC class I peptide presentation by functioning as a peptide exchange catalyst. eLife 4, e09617 (2015). doi:10.7554/eLife.09617 Medline

16. G. I. Morozov, H. Zhao, M. G. Mage, L. F. Boyd, J. Jiang, M. A. Dolan, R. Venna, M. A. Norcross, C. P. McMurtrey, W. Hildebrand, P. Schuck, K. Natarajan, D. H. Margulies, Interaction of TAPBPR, a tapasin homolog, with MHC-I molecules promotes peptide editing. Proc. Natl. Acad. Sci. U.S.A. 113, E1006-E1015 (2016). doi:10.1073/pnas.1519894113 Medline

17. C. Hermann, L. M. Strittmatter, J. E. Deane, L. H. Boyle, The binding of TAPBPR and Tapasin to MHC class I is mutually exclusive. J. Immunol. 191, 5743-5750 (2013). doi:10.4049/jimmunol.1300929 Medline

18. G. Dong, P. A. Wearsch, D. R. Peaper, P. Cresswell, K. M. Reinisch, Insights into MHC class I peptide loading from the structure of the tapasin-ERp57 thiol oxidoreductase heterodimer. Immunity 30, 21-32 (2009). doi:10.1016/j.immuni.2008.10.018 Medline

19. S. M. Thirdborough, J. S. Roddick, J. N. Radcliffe, M. Howarth, F. K. Stevenson, T. Elliott, Tapasin shapes immunodominance hierarchies according to the kinetic stability of peptide-MHC class I complexes. Eur. J. Immunol. 38, 364-369 (2008). doi:10.1002/eji.200737832 Medline

20. D. S. Boulanger, R. Oliveira, L. Ayers, S. H. Prior, E. James, A. P. Williams, T. Elliott, Absence of tapasin alters immunodominance against a lymphocytic choriomeningitis virus polytope. J. Immunol. 184, 73-83 (2010). doi:10.4049/jimmunol.0803489 Medline

21. N. Garbi, P. Tan, A. D. Diehl, B. J. Chambers, H.-G. Ljunggren, F. Momburg, G. J. Hämmerling, Impaired immune responses and altered peptide repertoire in tapasin-deficient mice. Nat. Immunol. 1, 234-238 (2000). doi:10.1038/79775 Medline

22. T. Elliott, V. Cerundolo, J. Elvin, A. Townsend, Peptide-induced conformational change of the class I heavy chain. Nature 351, 402-406 (1991). doi: $10.1038 / 351402 \mathrm{a} 0$ Medline

23. Materials and methods are available as supplementary materials.

24. G. Fleischmann, O. Fisette, C. Thomas, R. Wieneke, F. Tumulka, C. Schneeweiss, S. Springer, L. V. Schäfer, R. Tampé, Mechanistic basis for epitope proofreading in the peptide-loading complex. J. Immunol. 195, 4503-4513 (2015). doi:10.4049/jimmunol.1501515 Medline

25. A. Achour, J. Michaëlsson, R. A. Harris, H.-G. Ljunggren, K. Kärre, G. Schneider, T. Sandalova, Structural basis of the differential stability and receptor specificity of $\mathrm{H}-2 \mathrm{Db}$ in complex with murine versus human beta2-microglobulin. J. Mol. Biol. 356, 382-396 (2006). doi:10.1016/j.jmb.2005.11.068 Medline

26. M. Bouvier, D. C. Wiley, Importance of peptide amino and carboxyl termini to the stability of MHC class I molecules. Science 265, 398-402 (1994). doi:10.1126/science. 8023162 Medline

27. E. T. Abualrous, S. K. Saini, V. R. Ramnarayan, F. T. Ilca, M. Zacharias, S. Springer, The carboxy terminus of the ligand peptide determines the stability of the MHC class I molecule H-2Kb: A combined molecular dynamics and experimental study. PLOS ONE 10, e0135421 (2015). doi:10.1371/journal.pone.0135421 Medline

28. C. Thomas, R. Tampé, Proofreading of peptide-MHC complexes through dynamic multivalent interactions. Front. Immunol. 8, 65 (2017). doi:10.3389/fimmu.2017.00065 Medline

29. W. Pos, D. K. Sethi, M. J. Call, M.-S. E. D. Schulze, A.-K. Anders, J. Pyrdol, K. W. Wucherpfennig, Crystal structure of the HLA-DM-HLA-DR1 complex defines mechanisms for rapid peptide selection. Cell 151, 1557-1568 (2012). doi:10.1016/i.cell.2012.11.025 Medline

30. A. W. Purcell, J. J. Gorman, M. Garcia-Peydró, A. Paradela, S. R. Burrows, G. H. Talbo, N. Laham, C. A. Peh, E. C. Reynolds, J. A. López De Castro, J. McCluskey, Quantitative and qualitative influences of tapasin on the class I peptide repertoire. J. Immunol. 166, 1016-1027 (2001). 
doi:10.4049/iimmunol.166.2.1016 Medline

31. A. Neerincx, C. Hermann, R. Antrobus, A. van Hateren, H. Cao, N. Trautwein, S. Stevanović, T. Elliott, J. E. Deane, L. H. Boyle, TAPBPR bridges UDPglucose:glycoprotein glucosyltransferase 1 onto MHC class I to provide quality control in the antigen presentation pathway. elife 6, e23049 (2017). doi:10.7554/eLife.23049 Medline

32. Z. Zhang, W. J. Henzel, Signal peptide prediction based on analysis of experimentally verified cleavage sites. Protein Sci. 13, 2819-2824 (2004). doi:10.1110/ps.04682504 Medline

33. B. Rodenko, M. Toebes, S. R. Hadrup, W. J. E. van Esch, A. M. Molenaar, T. N. M. Schumacher, H. Ovaa, Generation of peptide-MHC class I complexes through UV-mediated ligand exchange. Nat. Protoc. 1, 1120-1132 (2006). doi:10.1038/nprot.2006.121 Medline

34. A. Casanas, R. Warshamanage, A. D. Finke, E. Panepucci, V. Olieric, A. Nöll, R. Tampé, S. Brandstetter, A. Förster, M. Mueller, C. Schulze-Briese, O. Bunk, M. Wang, EIGER detector: Application in macromolecular crystallography. Acta $\begin{array}{llllll}\text { Crystallogr. D Struct. Biol. 72, 1036-1048 (2016). } & \end{array}$ doi:10.1107/S2059798316012304 Medline

35. W. Kabsch, Xds. Acta Crystallogr. D Biol. Crystallogr. 66, 125-132 (2010). doi:10.1107/S0907444909047337 Medline

36. A. J. McCoy, R. W. Grosse-Kunstleve, P. D. Adams, M. D. Winn, L. C. Storoni, R. J. Read, Phaser crystallographic software. J. Appl. Crystallogr. 40, 658-674 (2007). doi:10.1107/S0021889807021206 Medline

37. Collaborative Computational Project, Number 4, The CCP4 suite: Programs for protein crystallography. Acta Crystallogr. D Biol. Crystallogr. 50, 760-763 (1994). doi:10.1107/S0907444994003112 Medline

38. K. Iwata, T. Matsuura, K. Sakurai, A. Nakagawa, Y. Goto, High-resolution crystal structure of beta2-microglobulin formed at pH 7.0. J. Biochem. 142, 413-419 (2007). doi:10.1093/ib/mvm148 Medline

39. A. Šali, T. L. Blundell, Comparative protein modelling by satisfaction of spatial restraints. J. Mol. Biol. 234, 779-815 (1993). doi:10.1006/jmbi.1993.1626 Medline

40. P. Emsley, K. Cowtan, Coot: Model-building tools for molecular graphics. Acta

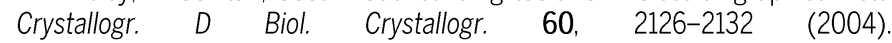
doi:10.1107/S0907444904019158 Medline

41. P. V. Afonine, R. W. Grosse-Kunstleve, N. Echols, J. J. Headd, N. W. Moriarty, M. Mustyakimov, T. C. Terwilliger, A. Urzhumtsev, P. H. Zwart, P. D. Adams, Towards automated crystallographic structure refinement with phenix.refine. Acta Crystallogr. D Biol. Crystallogr. 68, 352-367 (2012). doi:10.1107/S0907444912001308 Medline

42. L. Li, Y. Muzahim, M. Bouvier, Crystal structure of adenovirus E3-19K bound to HLA-A2 reveals mechanism for immunomodulation. Nat. Struct. Mol. Biol. 19, 1176-1181 (2012). doi:10.1038/nsmb.2396 Medline

43. B. E. Gewurz, R. Gaudet, D. Tortorella, E. W. Wang, H. L. Ploegh, D. C. Wiley, Antigen presentation subverted: Structure of the human cytomegalovirus protein US2 bound to the class I molecule HLA-A2. Proc. Natl. Acad. Sci. U.S.A. 98, 6794-6799 (2001). doi:10.1073/pnas.121172898 Medline

44. B. E. Willcox, L. M. Thomas, P. J. Bjorkman, Crystal structure of HLA-A2 bound to LIR-1, a host and viral major histocompatibility complex receptor. Nat. Immunol. 4, 913-919 (2003). doi:10.1038/ni961 Medline

45. G. F. Gao, J. Tormo, U. C. Gerth, J. R. Wyer, A. J. McMichael, D. I. Stuart, J. I. Bell, E. Y. Jones, B. K. Jakobsen, Crystal structure of the complex between human CD8 $\alpha \propto$ and HLA-A2. Nature 387, 630-634 (1997). doi:10.1038/42523 Medline

46. W. H. McCoy 4th, X. Wang, W. M. Yokoyama, T. H. Hansen, D. H. Fremont, Structural mechanism of ER retrieval of MHC class I by cowpox. PLOS Biol. 10, e1001432 (2012). doi:10.1371/journal.pbio.1001432 Medline

47. J. P. Vivian, R. C. Duncan, R. Berry, G. M. O'Connor, H. H. Reid, T. Beddoe, S. Gras, P. M. Saunders, M. A. Olshina, J. M. L. Widjaja, C. M. Harpur, J. Lin, S. M. Maloveste, D. A. Price, B. A. P. Lafont, D. W. McVicar, C. S. Clements, A. G. Brooks, J. Rossjohn, Killer cell immunoglobulin-like receptor 3DL1-mediated recognition of human leukocyte antigen B. Nature 479, 401-405 (2011). doi:10.1038/nature10517 Medline

48. E. J. Petrie, C. S. Clements, J. Lin, L. C. Sullivan, D. Johnson, T. Huyton, A. Heroux, H. L. Hoare, T. Beddoe, H. H. Reid, M. C. J. Wilce, A. G. Brooks, J. Rossjohn, CD94-NKG2A recognition of human leukocyte antigen (HLA)-E bound to an HLA class I leader sequence. J. Exp. Med. 205, 725-735 (2008). doi:10.1084/jem.20072525 Medline

49. K. C. Garcia, M. Degano, L. R. Pease, M. Huang, P. A. Peterson, L. Teyton, I. A Wilson, Structural basis of plasticity in T cell receptor recognition of a self peptide-MHC antigen. Science 279, 1166-1172 (1998) doi:10.1126/science. 279.5354 .1166 Medline

50. A. P. Uldrich, J. Le Nours, D. G. Pellicci, N. A. Gherardin, K. G. McPherson, R. T. Lim, O. Patel, T. Beddoe, S. Gras, J. Rossjohn, D. I. Godfrey, CDld-lipid antigen recognition by the $\gamma \delta$ TCR. Nat. Immunol. 14, 1137-1145 (2013) doi:10.1038/ni.2713 Medline

\section{ACKNOWLEDGMENTS}

We are grateful to Dr. S. Trowitzsch, C. Le Gal, and all members of the lab for their helpful comments on the manuscript. We thank the staff of the X06SA (PXI) beamline at the Swiss Light Source of the Paul Scherrer Institute for their support. We thank Dr. M. Braner for the peptide synthesis. This research was supported by the German Research Foundation (SFB 807, Membrane transport and communication and GRK 1986 to R.T.) and the Volkswagen Foundation (91067 to R.T.). Coordinates and structure factors have been deposited in the Protein Data Bank of the Research Collaboratory for Structural Bioinformatics with accession code 50PI. C.T. produced proteins, grew crystals, collected data, and determined the structure of the TAPBPR-MHC I complex. C.T. and R.T. interpreted the structure and wrote the manuscript. R.T. conceived the project.

\section{SUPPLEMENTARY MATERIALS}

www.sciencemag.org/cgi/content/full/science.aa06001/DC1

Materials and Methods

Figs. S1 to S7

Table S1

References (32-50)

8 August 2017; accepted 20 September 2017

Published online 12 October 2017

10.1126/science.aa06001 

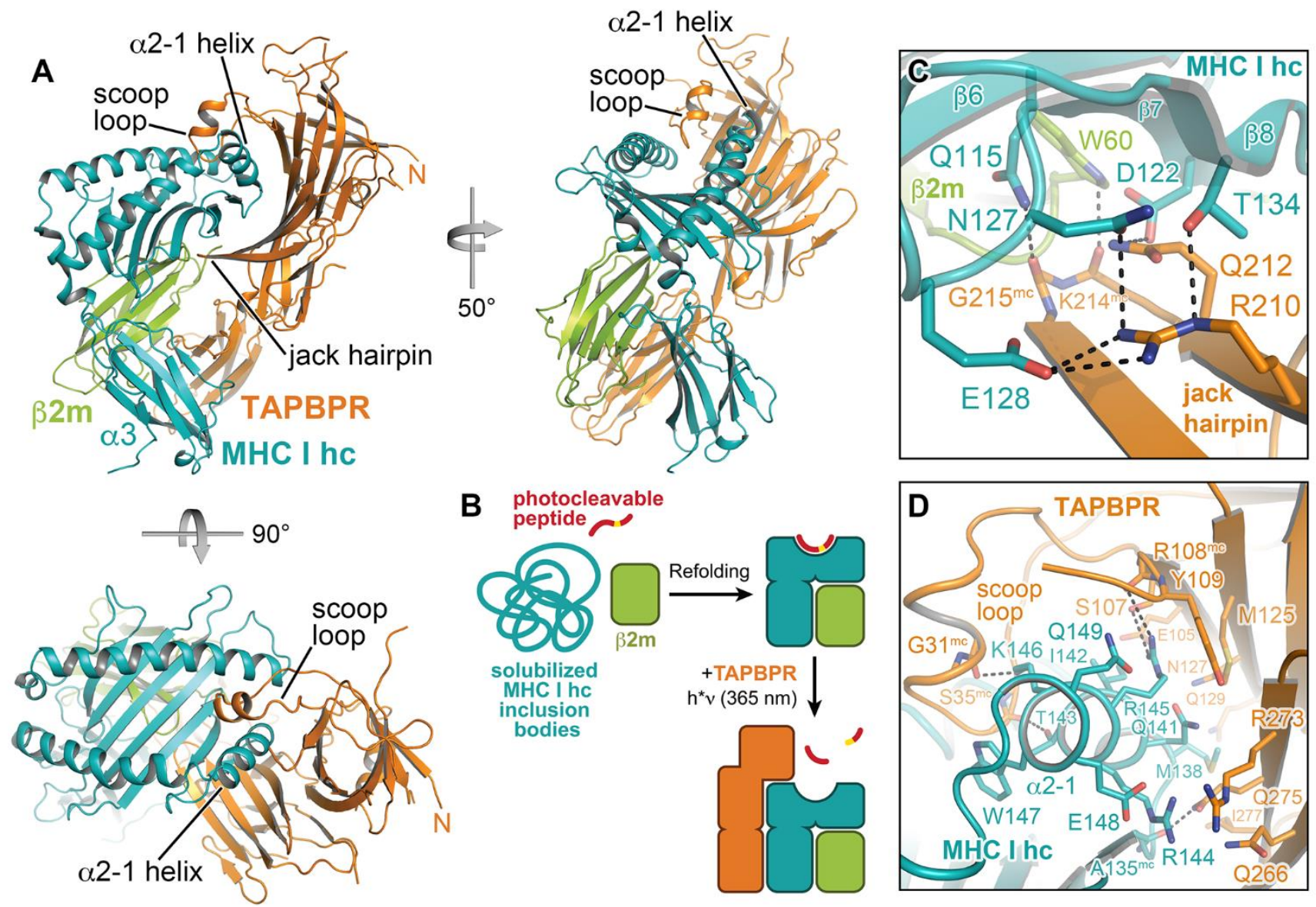

Fig. 1. Overview of the TAPBPR-MHC I complex. (A) Cartoon representation of the peptide-free TAPBPR-MHC I structure in different orientations. $\beta 2 \mathrm{~m}, \beta 2$-microglobulin; MHC I hc, MHC I heavy chain; $\alpha 3, \alpha 3$ domain of the hc; N, N-terminus. (B) Principle of complex formation between MHC I heavy chain, $\beta 2$ microglobulin, and TAPBPR, utilizing a photocleavable peptide. (C) Magnification of the interface formed between the jack hairpin of TAPBPR and the MHC I hc and $\beta 2 \mathrm{~m}$. Salt bridges and hydrogen bonds are indicated by dashed lines. (D) Magnification of the interface formed between the N-terminal domain of TAPBPR and the $\alpha 2-1$ region of the MHC I heavy chain. The dashed lines represent hydrogen bonds. mc, main-chain atoms. 

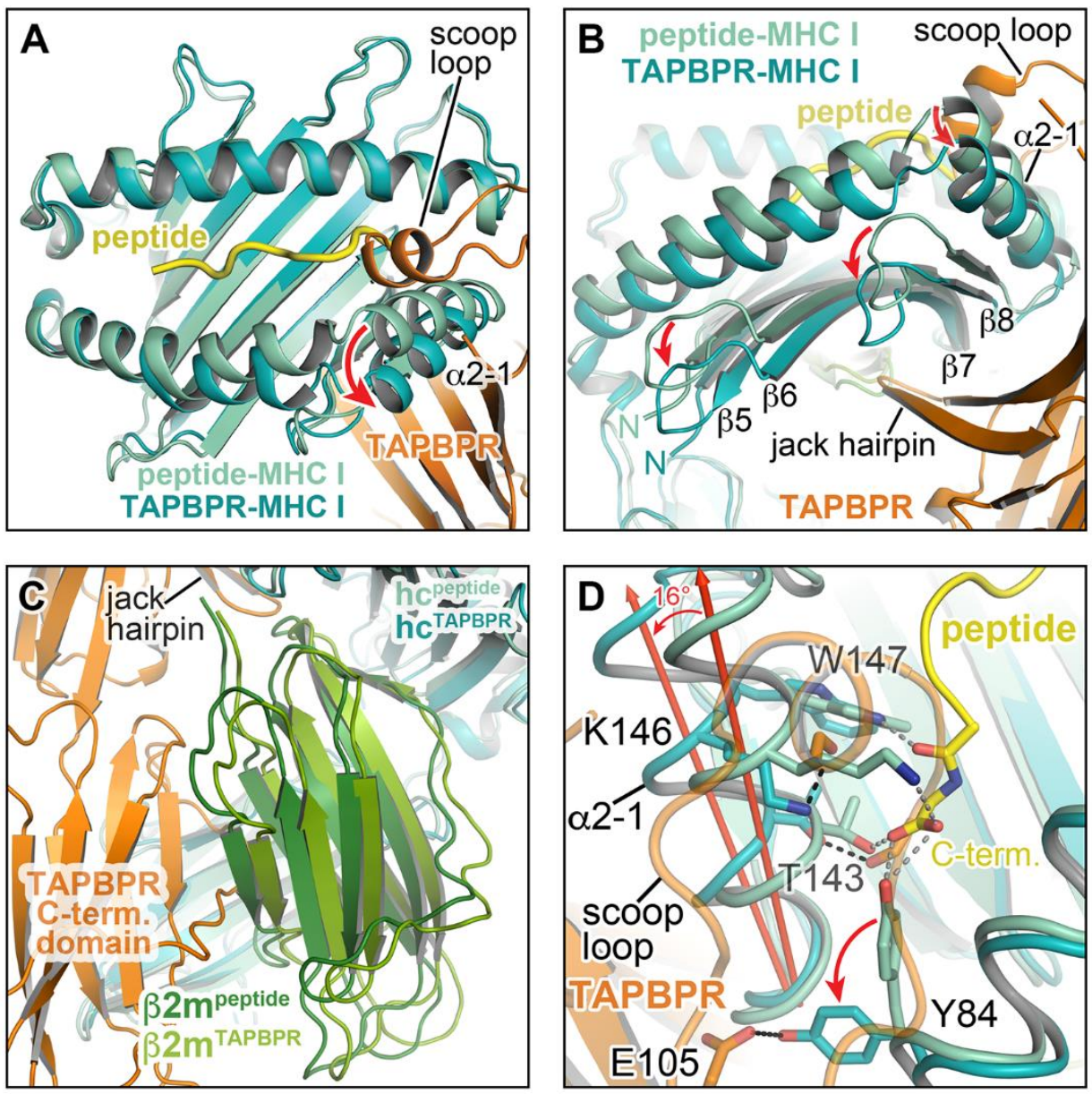

Fig. 2. TAPBPR-induced conformational changes in MHC I heavy chain and positional shift of $\beta 2 \mathrm{~m}$. (A) Superposition of peptide-free $\mathrm{H} 2-\mathrm{D}^{\mathrm{b}}$ of the TAPBPR complex (teal) with peptide-bound H2-D (PDB ID: 2F74) (cyan), top view onto peptide-binding groove. (B) Superposition as in A, but side-view of peptide-binding groove. N, N-terminus. (C) Positional shift of $\beta 2 \mathrm{~m}$ in superposition of TAPBPR-complexed $\mathrm{H} 2-\mathrm{D}^{\mathrm{b}}$ and peptide-bound $H 2-D^{b}$. hc, heavy chain. (D) View onto F-pocket region in superposition of TAPBPR-complexed $\mathrm{H}_{2}-\mathrm{D}^{\mathrm{b}}$ (teal) and peptide-bound $\mathrm{H}_{2}-\mathrm{D}^{\mathrm{b}}$ (cyan). Hydrogen bonds in the peptide-bound state are shown as grey dashed lines, hydrogen bonds in the peptide-free TAPBPR-bound state are indicated by black dashed lines. C-term., C-terminus. 


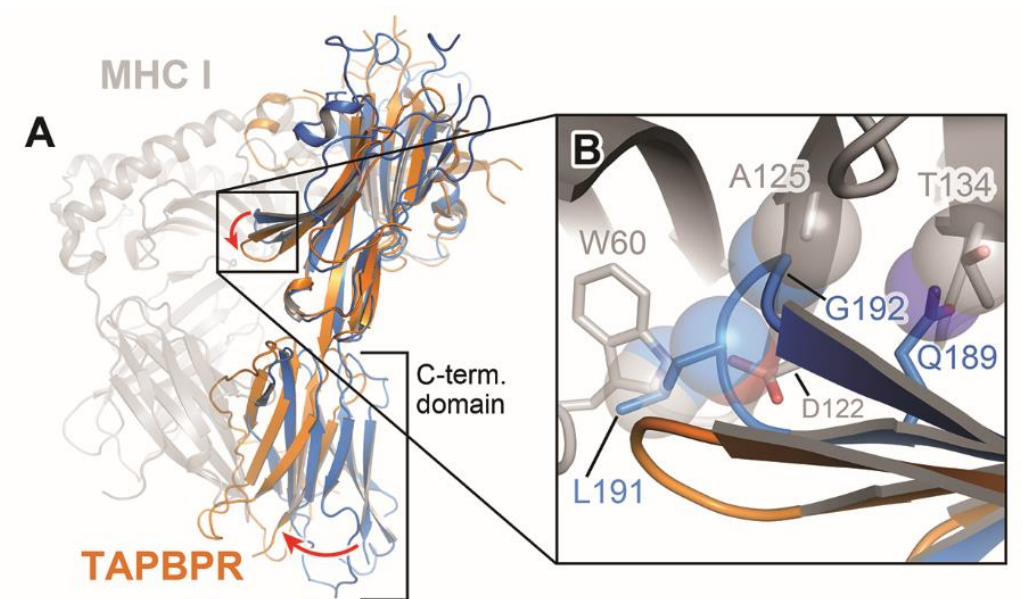

Tapasin

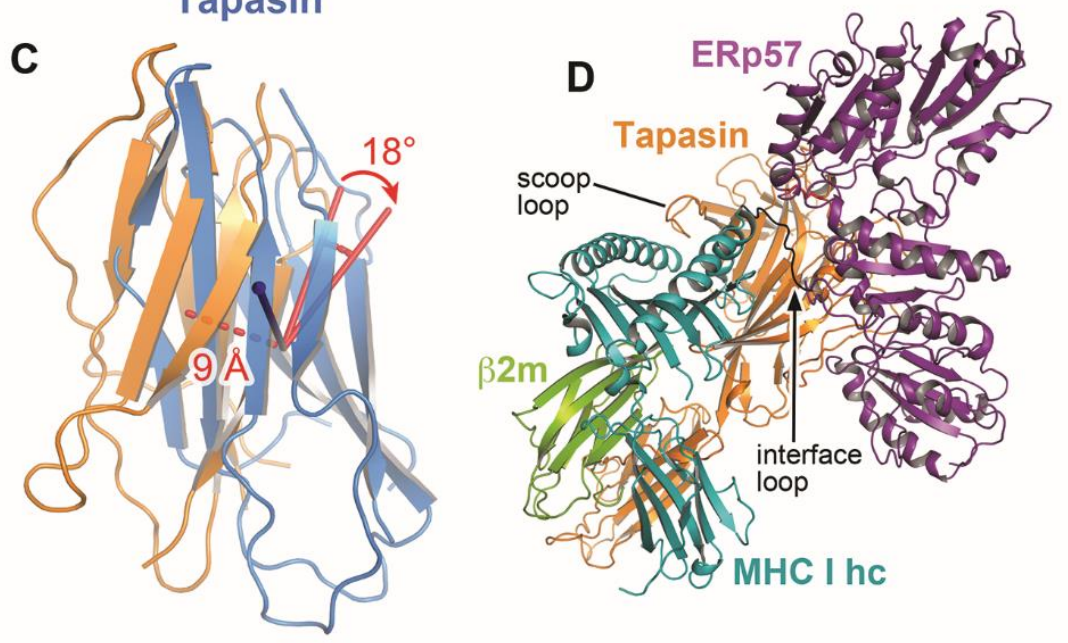

Fig. 3. Conformational plasticity in TAPBPR and Tsn. (A) To analyze conformational changes in the editors upon MHC I binding, the $\mathrm{N}$-terminal Tsn domain (PDB ID: 3F8U) was superimposed onto the $\mathrm{N}$-terminal TAPBPR domain of the TAPBPR-MHC I complex. C-term., C-terminal. (B), Magnification of the jack-hairpin region. The transparent spheres show the van der Waals radii of the most severely clashing non-hydrogen atoms of Tsn (blue) and MHC I (grey). (C) Magnification of the rigid-body movement observed for the $\mathrm{C}$-terminal domains of Tsn and TAPBPR, consisting of a translation by $9 \AA$ and $a$ rotation by 18 degree. (D) Model of the Tsn-ERp57-MHC I complex, based on the TAPBPR-MHC I X-ray structure. The intermolecular disulfide bridge between Tsn and ERp57 is indicated by red sticks. A loop in the $\alpha 2-1$ interface, which is stabilized in Tsn by ERp57, but is disordered in TAPBPR, is shown in black.. 

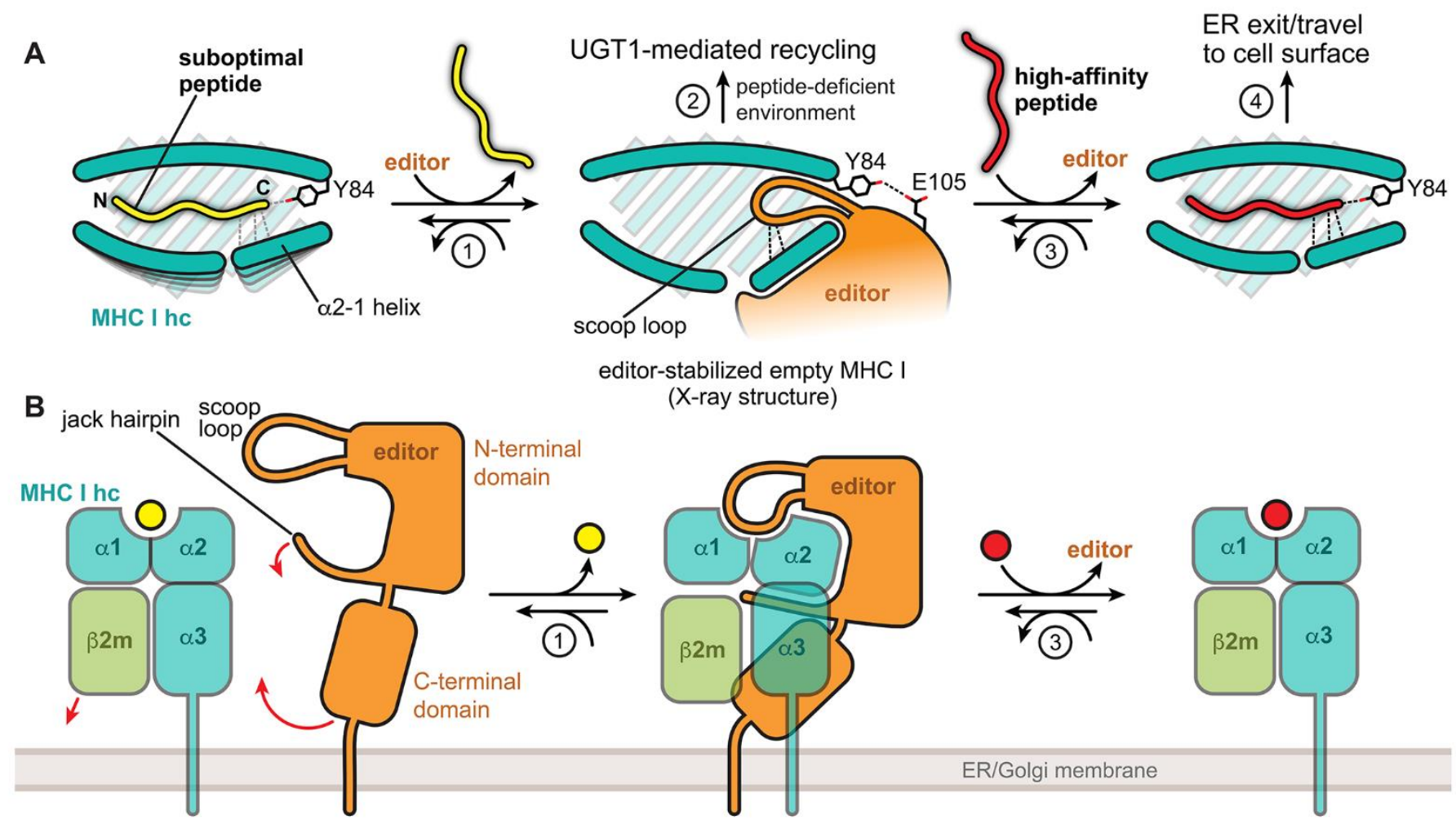

Fig. 4. Mechanistic model of catalyzed peptide proofreading. (A) Events in the peptide-binding groove during catalyzed proofreading. The peptide editors Tsn and TAPBPR sample the quality of MHC I-bound peptide epitopes with regard to their affinity by scanning the $\alpha 2-1$-helix region, which is crucially involved in anchoring the C-terminal portion of the peptide (step 1). Polar interactions are indicated by dotted lines. Upon encountering a suboptimally loaded $\mathrm{MHC}$ I molecule, the editors stabilize the peptide-binding groove in a widened conformation and render key peptide-coordinating residues inaccessible, including Y84, by inserting the scoop loop into the groove. As a consequence, the peptide dissociates. In the case of TAPBPR and in a peptide-deficient cellular environment, the resulting empty $\mathrm{MHC}$ I may be recycled via the TAPBPR-associating glucosyltransferase UGT1 (step 2). In the presence of high-affinity peptides, however, the editor is displaced (step 3), and the stable peptide-MHC I complex can travel to the cell surface (step 4). (B) Overview of domain movements and conformational changes during proofreading catalysis. Movements are indicated by red arrows. Low- and high-affinity peptides are shown as yellow and red circles, respectively. 